\title{
Using breath carbon monoxide to validate self- reported tobacco smoking in remote Australian Indigenous communities
}

David J MacLaren ${ }^{1 *}$, Katherine M Conigrave ${ }^{2,3}$, Jan A Robertson ${ }^{1}$, Rowena G Ivers ${ }^{4}$, Sandra Eades ${ }^{5}$, Alan R Clough ${ }^{1,6}$

\begin{abstract}
Background: This paper examines the specificity and sensitivity of a breath carbon monoxide (BCO) test and optimum BCO cutoff level for validating self-reported tobacco smoking in Indigenous Australians in Arnhem Land, Northern Territory (NT).

Methods: In a sample of 400 people ( $\geq 16$ years) interviewed about tobacco use in three communities, both selfreported smoking and BCO data were recorded for 309 study participants. Of these, 249 reported smoking tobacco within the preceding 24 hours, and 60 reported they had never smoked or had not smoked tobacco for $\geq 6$ months. The sample was opportunistically recruited using quotas to reflect age and gender balances in the communities where the combined Indigenous populations comprised 1,104 males and 1,215 females ( $\geq 16$ years). Local Indigenous research workers assisted researchers in interviewing participants and facilitating BCO tests using a portable hand-held analyzer.
\end{abstract}

Results: A BCO cutoff of $\geq 7$ parts per million (ppm) provided good agreement between self-report and BCO ( $96.0 \%$ sensitivity, $93.3 \%$ specificity). An alternative cutoff of $\geq 5 \mathrm{ppm}$ increased sensitivity from $96.0 \%$ to $99.6 \%$ with no change in specificity (93.3\%). With data for two self-reported nonsmokers who also reported that they smoked cannabis removed from the analysis, specificity increased to $96.6 \%$.

Conclusion: In these disadvantaged Indigenous populations, where data describing smoking are few, testing for BCO provides a practical, noninvasive, and immediate method to validate self-reported smoking. In further studies of tobacco smoking in these populations, cannabis use should be considered where self-reported nonsmokers show high $\mathrm{BCO}$.

\section{Introduction}

Over the past two decades, smoking rates in Australia have halved in the general population from $35 \%$ to $18 \%$ with predictions of $14 \%$ by 2020 [1]. However, for Indigenous Australians, smoking rates appear to have remained unchanged. Nationally, $51 \%$ of Indigenous men and $47 \%$ of Indigenous women report to be regular smokers[2].Smoking rates vary across Indigenous Australian populations. For example, much higher rates of between $59 \%$ to $83 \%[3-8]$ have been documented in some remote communities of the Northern Territory

\footnotetext{
* Correspondence: david.maclaren@jcu.edu.au

'School of Public Health, Tropical Medicine and Rehabilitation Sciences, James Cook University, Cairns, Queensland, Australia
}

(NT), with up to $92 \%$ of people reporting a history of tobacco use in one community[3].

Indigenous Australians experience a burden of disease 2.4 times that of non-Indigenous Australians[9], with the gap between Indigenous and non-Indigenous life expectancy at birth in 2009 estimated to be 11.5 years for men and 9.7 years for women[10]. About $12 \%$ of the burden of disease[9] and 20\% of indigenous deaths[11] are attributable to tobacco use. In 2008, the Australian government made a commitment to "closing the gap" in Indigenous Australian life expectancy[12], including addressing smoking[13].

Documenting tobacco use in Indigenous communities has typically relied on self-report in surveys, with a few

\section{Biomed Central}


studies using biochemical markers to verify self-report. Urine cotinine has been used in both urban[14] and remote clinic-based studies[7]. However, this involves the complexities and cost of obtaining and testing a urine sample and does not provide an immediate assessment of smoking. Portable, hand-held Breath Carbon Monoxide (BCO) analyzers are tools used to immediately assess smoking status. They are suitable for both clinical and community-based studies[15-23] and are being used in a small number of Indigenous Australian settings[24-26]. The utility of BCO analyzers and optimum BCO cutoff to distinguish smokers and nonsmokers is being investigated in different populations around the world[27-36] with different cutoff levels recommended in different populations dependent on the intended use of the BCO test. These include: assessing antenatal smoking[15,16,36]; clinical or community surveys[17,22,27-29,32,33,37]; validating smoking cessation $[18,20,30]$; assessing passive smoking[17] or environmental pollution[35]; or investigating sociocultural patterns of smoking[23]. There is, however, no guidance for the optimum $\mathrm{BCO}$ cutoff level to validate selfreported tobacco smoking in community-based surveys in Indigenous Australian populations.

This paper examines the sensitivity and specificity of the BCO test and the optimal cutoff level to distinguish between smokers and nonsmokers in three remote Indigenous populations.

\section{Methods}

\section{Setting}

The study was conducted in three Arnhem Land communities with a combined Indigenous population of 3,770 , including 1,104 males and 1,215 females aged $\geq 16$ years. Contemporary life is strongly influenced by traditional social and cultural norms and practices, with more than 20 tribal groups and seven major language groups represented across the three communities[38]. English is a second or third language[39]. Tobacco was introduced in the $17^{\text {th }}$ century by Macassan traders from the Indonesian archipelago, and extended with the expansion of the pastoral industry and Christian missions during the early $20^{\text {th }}$ century[40].

\section{Sampling}

Between July 2008 and February 2009, 400 Indigenous people (aged $\geq 16$ ), comprising $15 \%$ of the targeted population, were interviewed in the baseline phase of a community-based intervention study.

Local community members were employed as research workers to assist in the recruitment of participants, to interpret when local language was required, and to assist with $\mathrm{BCO}$ testing. Given that random sampling is impractical and intrusive in these communities[41], participants were opportunistically invited to participate using quotas to reflect age and gender balances. Interviews occurred in public spaces or in people's homes.

\section{Community Survey: Self-reported tobacco smoking and BCO}

Using a structured questionnaire, participants were asked about smoking status, smoking history, and pattern of tobacco use. Interviews were conducted by authors DM, JR, and AC, in most cases with local research workers. Participants were asked: "Do you smoke tobacco?" If the participant answered yes, a series of questions including the type of tobacco product used, the amount used, when/how the participant started smoking, and time since last cigarette were asked. Participants were also asked if they chewed tobacco, smoked tobacco in a pipe, or smoked "tailor made" and/or "roll your own: cigarettes.

Where required, research workers from the local community were able to provide a personal assessment of study participants' smoking status[41], a feasible indicator given sharing tobacco is an integral component of the collective social fabric of community life[42].

BCO was measured at interview using a hand-held Bedfont piCO+Smokerlyzer (Bedfont Scientific, UK, http://www.bedfont.com). Participants were requested to inhale and hold their breath for 15 seconds before exhaling into the analyzer. A BCO cutoff of $\geq 7$ ppm was used as recommended by the manufacturer. The $\mathrm{BCO}$ analyzers used in the study were calibrated by the manufacturer in May 2008 before the survey commenced and recalibrated by DM, according to the manufacturer's specifications, in November 2008. In trials of survey procedures, the acceptability of using a portable $\mathrm{BCO}$ analyzer with this population proved to be high. During the study, it was the experience of DM, JR, and AC that using the $\mathrm{BCO}$ analyser attracted participants into the study. The immediate return of $\mathrm{BCO}$ results provided an opportunity for participants to actively engage in discussion about tobacco smoking and have direct benefit from participating.

\section{Data analysis and approvals}

Data were included in the analysis if: (i) self-reported smokers reported smoking tobacco within the preceding 24 hours; or (ii) self-reported nonsmokers reported never smoking tobacco or not smoking tobacco for $\geq 6$ months[43]. Given the short half-life of BCO, data from self-reported occasional tobacco smokers who reported last smoking tobacco greater than 24 hours previously were not included in the analysis.

Self-reported smoking and BCO level were analyzed descriptively using sensitivity and specificity percentages and a Receiver Operating Characteristics (ROC) analysis. 
Sensitivity was defined as the proportion of all selfreported smokers for whom there was a positive $\mathrm{BCO}$ test, i.e., a BCO level at or above cutoff ( $\geq 7 \mathrm{ppm})$. Specificity was the proportion of nonsmokers for whom there was a negative $\mathrm{BCO}$ test, i.e., a BCO level below cutoff point $(<7 \mathrm{ppm})$. Since a test should ideally have high sensitivity and high specificity, the average of sensitivity plus specificity was calculated for different cutoff points to find the highest level.

Ethics approval for the study was provided by the Human Research Ethics Committee of James Cook University (approval number H 3072) and the NT Department of Health and Families and Menzies School of Health Research (approval number 0707).

\section{Results}

Among the 400 people interviewed, 300 (75\%) reported they smoked tobacco, and 100 (25\%) reported they did not. Four of the 400 interviewed explicitly refused a $\mathrm{BCO}$ test, and 19 were in such poor health that a $\mathrm{BCO}$ test would have been unnecessarily intrusive. BCO was not tested in a further 57 people interviewed primarily because they had no time to take the BCO test $(n=40)$ or because a BCO analyzer was not available at the time of interview $(\mathrm{n}=17)$. The remaining 320 people who provided both a $\mathrm{BCO}$ test and information about their tobacco use included 260 who self-reported they smoked tobacco and 60 people who self-reported they did not smoke tobacco. Eleven of the 260 were occasional tobacco smokers and reported they had not smoked within the preceding 24 hours. In accordance with inclusion criteria, these 11 occasional smokers were not included in the analysis. Therefore, BCO tests for 249 self-reported smokers and 60 self-reported nonsmokers were analyzed. The proportions of self-reported smokers $(81 \%=249 / 309)$ and nonsmokers $(19 \%=60 /$ 309 ) in this subsample were similar to proportions of self-reported smokers (75\%) and nonsmokers (25\%) in the sample overall $(|z|=1.90, P=0.057)$.

\section{Sensitivity and Specificity}

Of the 249 self-reported smokers, 10 had BCO below the cutoff of $\geq 7 \mathrm{ppm}$ (96.0\% sensitivity), and of the 60 self-reported nonsmokers, four had BCO $\geq 7$ ppm $(93.3 \%$ specificity) (Table 1$)$.

Of the four self-reported nonsmokers with $\mathrm{BCO} \geq 7$ ppm, three were males, two of whom stated they did not smoke tobacco but smoked cannabis (BCO $8 \mathrm{ppm}$ and $33 \mathrm{ppm}$ ) (Figure 1). The third male (BCO 14 ppm) provided no comment, but local research workers later suggested that he smoked cannabis (Figure 1). One selfreported female nonsmoker with $\mathrm{BCO} \geq 7 \mathrm{ppm}$ (BCO 9 $\mathrm{ppm}$, Figure 1) provided no further detail at interview, and local research workers were not present at interview to assist in clarifying the discrepancy.

Nine of the 10 self-reported smokers with BCO level $<7 \mathrm{ppm}$ provided information about time since last cigarette. Five reported their last cigarette was smoked approximately 8-12 hours prior (including three whose last cigarette was smoked the previous evening). Two had smoked approximately six hours prior, and two had their last cigarette within two hours before testing (data not shown).

Table 2 shows changes in sensitivity and specificity at different BCO cut-offs. The highest average for the combined sensitivity and specificity (96\%) occurs at BCO cutoffs of $\geq 5 \mathrm{ppm}$ and $\geq 6 \mathrm{ppm}$ (Table 2 ).

\section{Alternative Cut-off Level}

If a cutoff level of $\geq 5 \mathrm{ppm}$ had been used in the study, the number of false negative tests in self-reported smokers would have been reduced by nine from 10 to 1 , a reduction in the proportion of negative tests from $15 \%$ to $2 \%$. Using a $\mathrm{BCO}$ cutoff of $\geq 5 \mathrm{ppm}$ would substantially increase the sensitivity in the study from $96.0 \%$ to 99.6\% with no change in specificity (93.3\%) (Table 2). However excluding data for the two male cannabis users who said they did not smoke tobacco from analysis increased specificity to $96.6 \%$ (data not shown).

An ROC analysis was performed to assess the diagnostic accuracy of BCO across the range of possible cutoff values (Figure 2). The significant contribution to the area under the curve $(\mathrm{AUC}=0.972, \mathrm{P}<0.001)$ at a BCO cutoff of $\geq 5 \mathrm{ppm}$ indicates the considerable power the $\mathrm{BCO}$ marker holds to discriminate between smokers and nonsmokers in this population. With the data for the two male self-reported cannabis smokers excluded from the ROC analysis, the area under the curve at a BCO cutoff of $\geq 5 \mathrm{ppm}$ increased marginally to AUC = 0.989 . For prevalence estimates in the sample, a cutoff level of $\geq 7 \mathrm{ppm}$ would have estimated a prevalence of $79 \%$ of smokers. Using a cutoff level of $\geq 5 \mathrm{ppm}$ would have estimated a prevalence of $82 \%$ of smokers. With data for the two male cannabis smokers excluded, using a cutoff level of $\geq 5 \mathrm{ppm}$ would have estimated tobacco smoking prevalence of $81 \%$, the proportion of selfreported smokers in the sample of 400 people interviewed in the study overall.

\section{Discussion}

These findings indicate that $\mathrm{BCO}$ can be effectively used to validate self-reported smoking in remote Australian Indigenous communities. The strong agreement between self-reported smoking and $\mathrm{BCO}$ indicates that selfreported smoking can be considered a reliable measure in this population. 
Table 1 Breath carbon monoxide (BCO) and self-reported smoking status

\begin{tabular}{|c|c|c|c|c|c|c|}
\hline \multirow[t]{2}{*}{ BCO level (p.p.m.) } & \multirow[t]{2}{*}{ Self-reported non-smokers (n) } & \multicolumn{4}{|c|}{ Self-reported smokers (n) in BCO range } & \multirow[t]{2}{*}{ Total $(\mathrm{n})$} \\
\hline & & 0-5 p.p.m. & 6-10 p.p.m. & 11-15 p.p.m. & $>15$ p.p.m. & \\
\hline 1 & 22 & & & & & 22 \\
\hline 2 & 20 & 1 & & & & 21 \\
\hline 3 & 11 & & & & & 11 \\
\hline 4 & 3 & & & & & 3 \\
\hline 5 & & 2 & & & & 2 \\
\hline 6 & & & 7 & & & 7 \\
\hline$\geq 7$ & 4 & & 42 & 66 & 131 & 243 \\
\hline Total & & & & & & 309 \\
\hline
\end{tabular}

Limitations of the study include that the sample was not randomly selected and so results cannot be generalized. However, participants were recruited to reflect each community's age and gender characteristics. Although BCO was not tested in all participants, the gender composition and proportions of self-reported smokers among those who provided a BCO test were similar to the sample overall. Confidence in the results is further reinforced by the high level of agreement between $\mathrm{BCO}$ and self-report, by the similarly high smoking rates found in other studies in the region, and because community members themselves informed researchers that results reflected their own family and community experience.
The community-based survey method recorded selfreported smoking status and immediately returned $\mathrm{BCO}$ test results to study participants. This allowed discrepancies between self-report and $\mathrm{BCO}$ to be investigated at the time of interview with further questions about smoking history or pattern of use, which assisted in refining the data.

Ten (4\%) self-reported smokers had BCO below the $\geq 7$ ppm cutoff. In nine of these, the self-reported time since last cigarette was between 2 and 12 hours prior to BCO test. Three of these nine had not smoked since the previous evening. Given that BCO has a half-life of between 3 and 4 hours and can decline by 2.1 to 7.5 ppm per hour, depending on the initial BCO level[44],

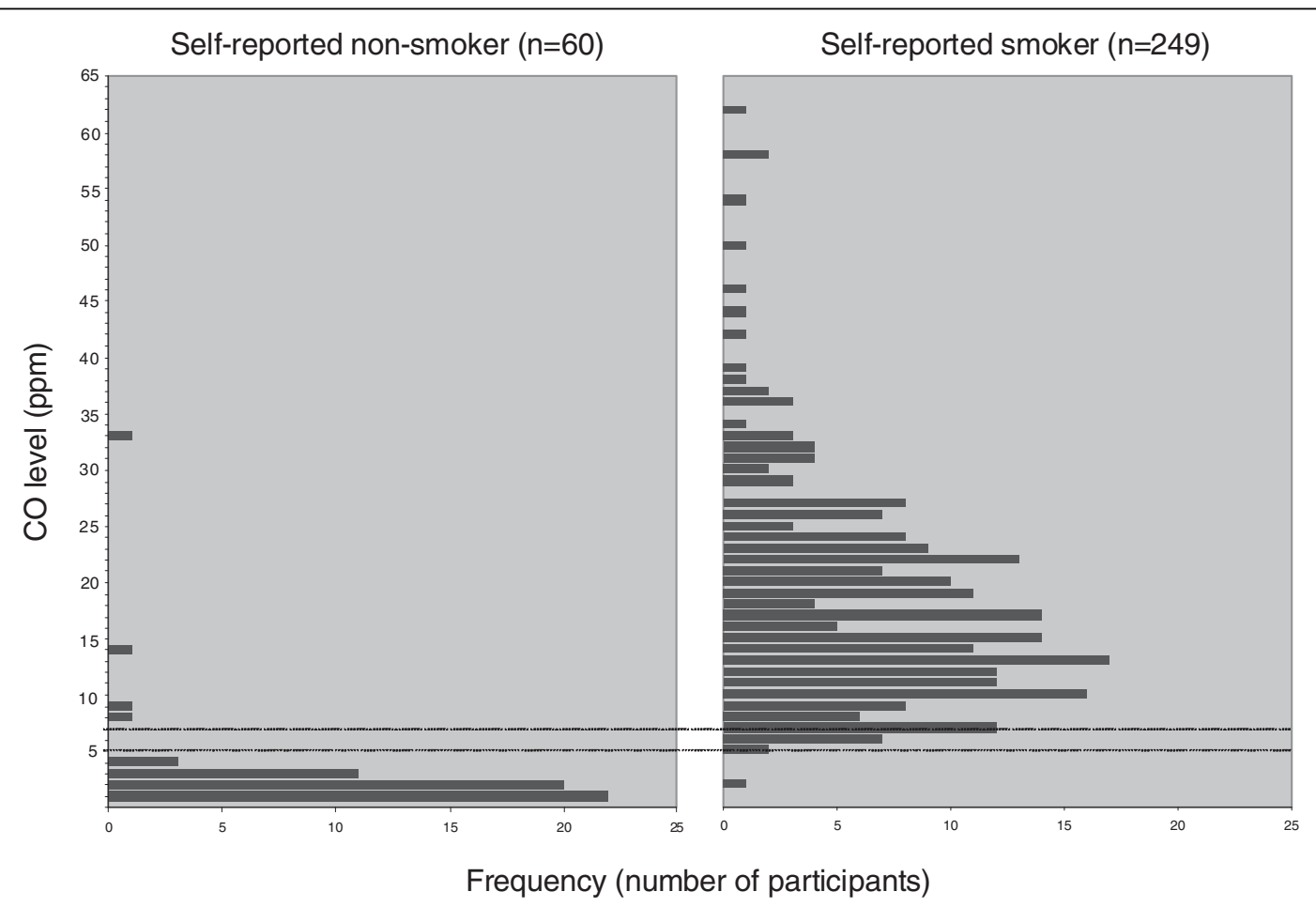

Figure 1 Bar chart for breath carbon monoxide (BCO) measurements for self-reported nonsmokers and smokers. The two lines indicate the cutoffs of $\geq 7 \mathrm{ppm}$ and $\geq 5 \mathrm{ppm}$. 
Table 2 Sensitivity and specificity of various breath carbon monoxide (BCO) cutoff levels

\begin{tabular}{cccc}
\hline $\begin{array}{c}\text { CO cut-off } \geq \\
\text { (p.p.m.) }\end{array}$ & Sensitivity & Specificity & (Sensitivity + specificity)/2 \\
\hline 1 & 1.000 & 0.000 & 0.50 \\
2 & 1.000 & 0.367 & 0.68 \\
3 & 0.996 & 0.700 & 0.85 \\
4 & 0.996 & 0.883 & 0.94 \\
5 & 0.996 & 0.933 & 0.96 \\
6 & 0.988 & 0.933 & 0.96 \\
7 & 0.960 & 0.933 & 0.95 \\
8 & 0.912 & 0.933 & 0.92 \\
9 & 0.888 & 0.950 & 0.92 \\
10 & 0.855 & 0.967 & 0.91 \\
\hline
\end{tabular}

there was sufficient time for $\mathrm{BCO}$ to decline below the cutoff. Smokers consistently reported periods of heavy and light smoking with a greater amount of tobacco smoked in the first few days after fortnightly paydays. Similar to smoking patterns documented in other Indigenous communities[42], the majority of participants reported regularly running out and frequently requesting tobacco from family and friends. This provides a plausible explanation for self-reported tobacco smokers who only smoke occasionally and/or have low BCO.
Although those who smoke few cigarettes per day can also have normal $\mathrm{BCO}[21,23,44]$, lapsed time since last cigarette, independent of the number of cigarettes smoked, accounted for most self-reported smokers with low BCO in this study.

The study also documented four (7\%) self-reported nonsmokers with $\mathrm{BCO} \geq 7 \mathrm{ppm}$. While such discrepancies may allude to false self-report or exposure to secondhand smoke, two of these four results could be accounted for by cannabis use. It is possible that exposure to secondhand smoke contributed to the small number of false positives in this study, however cannabis use in this population is likely to be an important factor. Studies of cannabis use in similar communities in the same region indicate that most cannabis users (94\%) blend cannabis with tobacco and smoke the mixture in handmade "bucket bongs," with tobacco smokers about 19 times more likely than nonsmokers to also smoke cannabis[45]. Given that up to two-thirds of males and half of females regularly use cannabis in the region's communities[45,46], cannabis use should be considered where self-reported nonsmokers show high BCO in further self-reported smoking validation studies. The present study did not systematically collect data about cannabis use at interview. A study investigating both

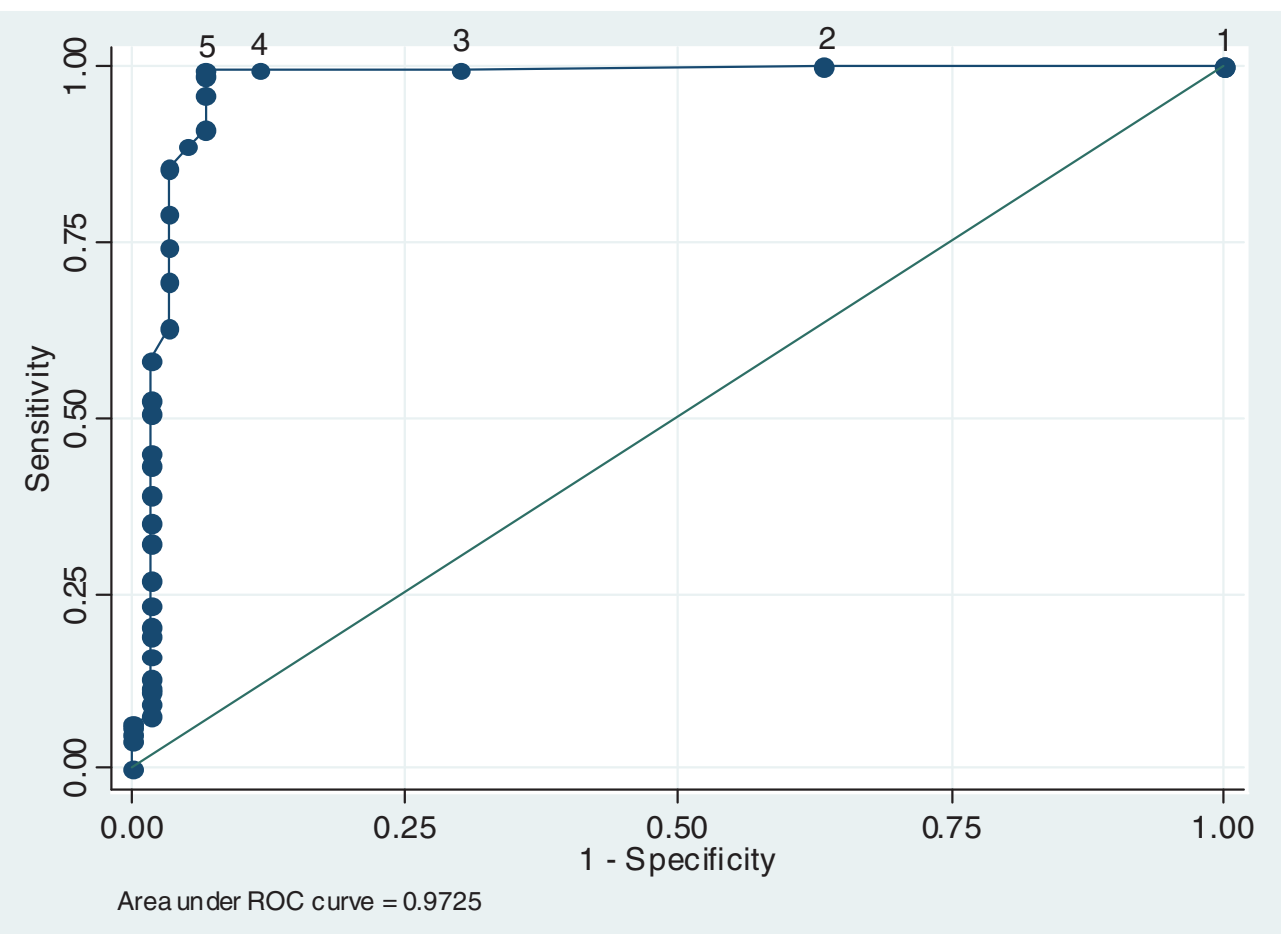

Figure 2 For receiver operating characteristic (ROC) analysis, using data for all participants, 1-specificity (x-axis) was plotted against sensitivity at breath carbon monoxide $(B C O)$ cutoff levels from $1 \mathrm{ppm}$ to $10 \mathrm{ppm}$. The numbers placed along the ROC curve indicate BCO cutoff levels. 
tobacco and cannabis smoking requires a different approach, including suitable protocols designed to minimize the ethical and legal risks of studying illegal behaviors in these disadvantaged and disempowered populations in Australia[45].

Only a few studies in Indigenous Australian populations have used biomarkers to verify self-reported smoking. A community-based study in an urban population recorded $10 \%$ of self-reported nonsmokers with $\mathrm{BCO}$ above cutoff of $9 \mathrm{ppm}$ [26], while a clinic-based study in a remote population tested $\mathrm{BCO}$ but did not analyze discrepancies[25]. Two clinic-based studies using urine cotinine, one remote and one urban, both found higher discrepancies. The remote study found $15 \%$ of selfreported nonsmokers produced levels above cutoff (539 nmom/l)[7], while the urban study found $17 \%$ of selfreported nonsmoking pregnant women produced levels above cutoff $(250 \mathrm{ng} / \mathrm{ml})[14]$. In the study reported here, $7 \%$ of self-reported nonsmokers had $\mathrm{BCO}$ above cutoff ( $\geq 7 \mathrm{ppm})$. Caution is, however, required before making direct comparison between these studies given the different population groups, recruitment methods, sample size, biomarkers, and study context.

A range of BCO cutoff levels has been used to validate self-reported smoking in different population groups around the world. Cutoffs as high as $10 \mathrm{ppm}$ have been used[20,47,48]. Others have used 9 ppm[22,26,37,44]; 8 ppm[19]; 7 ppm[28]; 6.5 ppm[17]; or 6 ppm[21]. Several studies recommend cutoffs as low as 2 to $3 \mathrm{ppm}$ $[29,31,36]$. However, self-reported smoking status and BCO level can vary between ethnic groups in the same location[23]. This suggests possible cultural or communication differences in responses to questions about smoking, a challenge well-known in remote Aboriginal communities[7,39]. Different sociocultural patterns of smoking may mean different BCO cutoffs are required in different populations. In this study population, reducing the BCO cutoff from $\geq 7 \mathrm{ppm}$ to $\geq 5 \mathrm{ppm}$ would increase the self-reported smokers verified from $96.0 \%$ to $99.6 \%$, while self-reported nonsmokers verified would remain unchanged at $93.3 \%$. With better information in future studies about those who smoke cannabis and not tobacco in these communities, the proportion of selfreported nonsmokers of tobacco verified could be as high as $96.6 \%$.

\footnotetext{
Acknowledgements

The authors wish to thank Professor Robert Gibberd and Professor Rob Sanson-Fisher, University of Newcastle, New South Wales, and Associate Professor Renée Bittoun, Central Clinical School, Brain and Mind Research Institute, University of Sydney. For reviewing the manuscript, thanks to Ms Marlene Thompson and Ms Michelle MacLaren, School of Public Health, Tropical Medicine and Rehabilitation Sciences, James Cook University, Cairns. This work was supported by the Australian National Health and Medical Research Council [Grant 436012]
}

\section{Author details}

${ }^{1}$ School of Public Health, Tropical Medicine and Rehabilitation Sciences, James Cook University, Cairns, Queensland, Australia. ${ }^{2}$ Drug Health Service, Royal Prince Alfred Hospital, Sydney, New South Wales, Australia. ${ }^{3}$ Sydney Medical School, University of Sydney, New South Wales, Australia. ${ }^{4}$ Illawarra Aboriginal Medical Service, Wollongong, New South Wales, Australia. ${ }^{5}$ Baker IDI Heart and Diabetes Institute, Melbourne, Victoria, Australia. ${ }^{6}$ School of Indigenous Australian Studies, James Cook University, Cairns, Queensland, Australia.

\section{Authors' contributions}

DM participated in collection, analysis, and interpretation of data, and drafted and edited the manuscript. KC made substantial contributions to the conception and design of the study, analyzed and interpreted data, and revised the manuscript. JR participated in collection of data and revised the manuscript. Rl participated in the conception and design of the study and revised the manuscript. SE participated in the conception and design of the study and revised the manuscript. AC led the conception and design of the study, participated in data collection, led the statistical analysis of results, and critically revised all sections for intellectual content. All authors read and approved the final manuscript.

\section{Competing interests}

The authors declare that they have no competing interests.

Received: 11 November 2009

Accepted: 20 February 2010 Published: 20 February 2010

\section{References}

1. Gartner CE, Barendregt JJ, Hall WD: Predicting the future prevalence of cigarette smoking in Australia: how low can we go and by when?. Tob Control 2009, tc.2008.027615.

2. Trewin D: National Aboriginal and Torres Strait Islander Health Survey. Australia 2004-05. Canberra: Australian Bureau of Statistics 2006.

3. Clough A, Robertson J, MacLaren D: The gap in tobacco use between remote Indigenous Australian communities and the Australian population can be closed. Tob Control 2009, 18:335-336.

4. Clough AR, Guyula T, Yunupingu M, Burns CB: Diversity of substance use in eastern Arnhem Land (Australia): patterns and recent changes. Drug Alcohol Rev 2002, 21:349-356.

5. Hoy WE, Norman RJ, Hayhurst BG, Pugsley DJ: A health profile of adults in a Northern Territory Aboriginal community, with an emphasis on preventable morbidities. Aust NZ J Public Health 1997, 21:121-126.

6. Ivers R, Castro A, Parfitt D, Bailie R, D'Abbs P, Richmond R: Evaluation of a multi-component community tobacco intervention in three remote Australian Aboriginal communities. Aust N Z J Public Health 2006, 30:132-136.

7. McDonald SP, Maguire GP, Hoy WE: Validation of self-reported cigarette smoking in a remote Australian Aboriginal community. Aust N Z J Public Health 2003, 27:57-60.

8. Watson C, Fleming J, Alexander K: A survey of drug use patterns in Northern Territory Aboriginal communities: 1986-1987. Darwin: Northern Territory Department of Health and Community Services, Drug and Alcohol Bureau 1988.

9. Vos T, Barker B, Begg S, Stanley L, Lopez AD: Burden of disease and injury in Aboriginal and Torres Strait Islander Peoples: the Indigenous health gap. Int J Epidemiol 2009, 38:470-477.

10. New estimates of Indigenous life expectancy released: ABS. http://www. abs.gov.au/AUSSTATS/abs@.nsf/0/C65F4C150DD0497ACA2575BE002656BC? OpenDocument.

11. Vos T, Barker B, Stanley L, Lopez A: The burden of disease and injury in Aboriginal and Torres Strait Islander peoples 2003. Brisbane: School of Population Health, The University of Queensland 2007.

12. Department of Families Housing Community Services and Indigenous Affairs: Closing the Gap on Indigenous Disadvantage: the challenge for Australia. Canberra Commonwealth of Australia 2009.

13. Rudd K: Joint Media Release with the Minister for Health and Ageing and the Minister for Indigenous Affairs - Rudd Government Tackles Indigenous Smoking Rates and Health Workforce in next Down Payments on Closing the Gap. Australia PMo ed. Canberra Commonwealth of Australia 2008. 
14. Gilligan C, Sanson-Fisher R, Eades S, Wenitong M, Panaretto K, D'Este C: Assessing the accuracy of self-reported smoking status and impact of passive smoke exposure among pregnant Aboriginal and Torres Strait Islander women using cotinine biochemical validation. Drug Alcohol Rev 2009, 9999.

15. Campbell E, Sanson-Fisher R, Walsh R: Smoking status in pregnant women: Assessment of self-report against carbon monoxide (CO). Addict Behav 2001, 26:1-9.

16. Campbell E, Walsh RA, Sanson-Fisher R, Burrows S, Stojanovski E: A group randomised trial of two methods for disseminating a smoking cessation programme to public antenatal clinics: effects on patient outcomes. Tob Control 2006, 15:97-102.

17. Deveci SE, Deveci F, Acik Y, Ozan AT: The measurement of exhaled carbon monoxide in healthy smokers and non-smokers. Respir Med 2004, 98:551-556.

18. Hung J, Lin CH, Wang JD, Chan CC: Exhaled carbon monoxide level as an indicator of cigarette consumption in a workplace cessation program in Taiwan. J Formos Med Assoc 2006, 105:210-213.

19. Jarvis MJ, Tunstall-Pedoe H, Feyerabend C, Vesey C, Saloojee Y: Comparison of tests used to distinguish smokers from nonsmokers. Am J Public Health 1987, 77:1435-1438

20. Jatlow P, Toll BA, Leary V, Krishnan-Sarin S, O'Malley SS: Comparison of expired carbon monoxide and plasma cotinine as markers of cigarette abstinence. Drug Alcohol Depend 2008, 98:203-209.

21. Middleton ET, Morice $\mathrm{AH}$ : Breath carbon monoxide as an indication of smoking habit. Chest 2000, 117:758-763.

22. Morabia A, Bernstein MS, Curtin F, Berode M: Validation of Self-Reported Smoking Status by Simultaneous Measurement of Carbon Monoxide and Salivary Thiocyanate. Prev Med 2001, 32:82-88.

23. Pearce MS, Hayes L, Newcastle Heart P, Newcastle Thousand Families S: Self-reported smoking status and exhaled carbon monoxide: results from two population-based epidemiologic studies in the North of England. Chest 2005, 128:1233-1238.

24. Adams K, Briggs V: Galnya Angin (Good Air) Partnerships in Indigenous Tobacco Control. Melbourne: Centre for Excellence in Tobacco Control 2005.

25. Ivers RG, Farrington M, Burns CB, Bailie RS, D'Abbs PH, Richmond RL, Tipiloura $\mathrm{E}$ : A study of the use of free nicotine patches by Indigenous people. Aust N Z J Public Health 2003, 27:486-490.

26. Perkins J, Sanson-Fisher R, Blunden S, Lunnay D, Redman S, Hensley M: The prevalence of drug use in urban Aboriginal communities. Addiction 1994, 89:1319-1331.

27. Chatkin J, Fritscher L, de Abreu C, Cavalet-Blanco D, Chatkin G, Wagner M, Fritscher $C$ : Exhaled carbon monoxide as a marker for evaluating smoking abstinence in a Brazilian population sample. Prim Care Respir J 2007, 16:36-40.

28. Chatrchaiwiwatana S, Ratanasiri A: Exhaled carbon monoxide level and smoking status in urban Khon Kaen adults. J Med Assoc Thai 2008 91:1669-1676.

29. Cropsey KL, Eldridge GD, Weaver MF, Villalobos GC, Stitzer ML: Expired Carbon Monoxide Levels in Self-Reported Smokers and Nonsmokers in Prison. Nicotine Tob Res 2006, 8:653-659.

30. Holt S, Timu-Parata C, Ryder-Lewis S, Weatherall M, Beasley R: Efficacy of bupropion in the indigenous Maori population in New Zealand. Thorax 2005, 60:120-123.

31. Javors $M$, Hatch J, Lamb R: Cut-off levels for breath carbon monoxide as a marker for cigarette smoking. Addiction 2005, 100:159-167.

32. Kentala J, Utriainen P, Pahkala K, Mattila K: Verification of adolescent selfreported smoking. Addict Behav 2004, 29:405-411.

33. Kunze U, Böhm G, Ferstl F, Groman E: Assessing smoking behaviour among medical students by the measurement of expired carbon monoxide (CO). WMW Wiener Medizinische Wochenschrift 2009, 159:14-16.

34. Lamb RJ, Morral AR, Kirby KC, Iguchi MY, Galbicka G: Shaping smoking cessation using percentile schedules. Drug Alcohol Depend 2004 76:247-259.

35. Shafiq M, Khan S, Khawaja MR, Haque S, Khan JA: Socio-demographic correlates of exhaled breath carbon monoxide in Karachi's adult population. J Pak Med Assoc 2008, 58:75-78.

36. Usmani Z, Craig P, Shipton D, Tappin D: Comparison of CO breath testing and women's self-reporting of smoking behaviour for identifying smoking during pregnancy. Subst Abuse Treat Prev Policy 2008, 3:4.
37. Jagoe K, Edwards R, Mugusi F, Whiting D, Unwin N: Tobacco smoking in Tanzania, East Africa: population based smoking prevalence using expired alveolar carbon monoxide as a validation tool. Tob Control 2002, 11:210-214.

38. Tindale N: Aboriginal tribes of Australia: their terrain environmental controls distribution limits and proper names Canberra: Australian National University Press 1974.

39. Trudgen Rl: Why warriors lie down and die: Djambatj mala towards an understanding of why Aboriginal people of Arnhem Land face the greatest crisis in health and education since European contact Darwin: Aboriginal Resource and Development Services 2000.

40. Brady M: Historical and cultural roots of tobacco use among Aboriginal and Torres Strait Islander people. Aust NZ J Publ Health 2002, 26:120-124.

41. Clough AR, Cairney S, D'abbs P, Parker R, Maruff P, Gray D, O'Reilly B: Measuring Exposure to Cannabis use and other Substance use in Remote Aboriginal Populations in Northern Australia: Evaluation of $A$ 'Community Epidemiology' Approach using Proxy Respondents. Addict Res Theory 2004, 12:261-274.

42. Johnston V, Thomas DP: Smoking behaviours in a remote Australian Indigenous community: The influence of family and other factors. Soc Sci Med 2008, 67:1708-1716.

43. West R, Hajek P, Stead L, Stapleton J: Outcome criteria in smoking cessation trials: proposal for a common standard. Addiction 2005, 100:299-303.

44. Leitch DN, Harkawat R, Askew J, Masel P, Hendrick DJ: Relation of expired carbon monoxide to smoking history, lapsed time, TLCO measurement and passive smoking. Respir Med 2005, 99:32-38.

45. Clough AR, D'Abbs P, Cairney S, Gray D, Maruff P, Parker R, O'Reilly B: Emerging patterns of cannabis and other substance use in Aboriginal communities in Arnhem Land, Northern Territory: a study of two communities. Drug Alcohol Rev 2004, 23:381-390.

46. Lee KS, Clough AR, Conigrave KM: High levels of cannabis use persist in Aboriginal communities in Arnhem Land, Northern Territory. Med J Aust 2007, 187:594-595

47. Jorenby DE, Smith SS, Fiore MC, Hurt RD, Offord KP, Croghan IT, Hays JT, Lewis SF, Baker TB: Varying nicotine patch dose and type of smoking cessation counseling. JAMA 1995, 274:1347-1352.

48. Tonnesen $\mathrm{P}$, Norregaard J, Mikkelsen $\mathrm{K}$, Jorgensen S, Nilsson F: A doubleblind trial of a nicotine inhaler for smoking cessation. JAMA 1993, 269:1268-1271.

doi:10.1186/1478-7954-8-2

Cite this article as: MacLaren et al:: Using breath carbon monoxide to validate self-reported tobacco smoking in remote Australian Indigenous communities. Population Health Metrics 2010 8:2.

\section{Submit your next manuscript to BioMed Central and take full advantage of:}

- Convenient online submission

- Thorough peer review

- No space constraints or color figure charges

- Immediate publication on acceptance

- Inclusion in PubMed, CAS, Scopus and Google Scholar

- Research which is freely available for redistribution

Submit your manuscript at www.biomedcentral.com/submit
Biomed Central 